\title{
CONCENTRACIONES VERTICALES EN LAS MINAS DE VIZCAYA (1871-1936)
}

ANTONIO ESCUDERO

Universidad de Alicante

\section{RESUMEN}

El artículo consta de tres partes. Explico primero por qué las grandes casas siderúrgicas europeas optaron por concentrar verticalmente parte del criadero vasco con sus fábricas. Ofrezco luego información sobre las cuatro empresas mineras integradas con la siderurgia continental (Bilbao Iron Ore, Luchana Mining, Orconera y Franco Belga). Para terminar, sostengo que la existencia de estas y otras concentraciones verticales en la minería española obliga a reconsiderar algunos aspectos de la polémica «pesimistas»-uoptimistas» (beneficios de las compañías extranjeras, balanza comercial y relaciones de intercambio).

\section{ABSTRACT}

The paper is divided in three parts. Firstly I explain why the big steel and iron European firms decided to concentrate vertically a part of the Vasc mining sector with their plants. Then I analyse the four mining firms which were integrated in the continental iron and steel industry (Bilbao Iron Ore, Luchana Mining, Orconera and Franco Belga). Finally I defend the idea that the existence of these and other vertical concentrations in the Spanish mining sector force us to reconsider some of the topics in the controversy between pessimists and optimists (foreign firms benefits, trade balance and terms of trade).

Este trabajo consta de tres partes. Explico primero las estrategias empresariales a las que condujo el interés de la siderurgia europea por el criadero de Somorrostro. Ofrezco luego información sobre las compañías mineras vizcaínas integradas verticalmente con fábricas de acero extranjeras. 
Para concluir, relaciono estas y otras concentraciones verticales con el polémico coste de oportunidad de la política minera española.

\section{EL INTERÉS DE LA SIDERURGIA EUROPEA POR LAS MINAS DE VIZCAYA. ESTRATEGIAS EMPRESARIALES (1870-1875)}

Las primeras producciones inglesas Bessemer utilizaron lingote fabricado con minerales sin fósforo de Cumberland y Lancashire. Al iniciarse la década de 1870 , la insuficiente oferta de estas menas elevó sus precios comprometiendo la fabricación de acero a costes competitivos ${ }^{1}$. Fue entonces cuando la siderurgia británica se vio abocada a encontrar minerales puros en el exterior ${ }^{2}$. El problema no sólo afectó al Reino Unido. Francia, Bélgica y Alemania carecían de menas sin fósforo, de manera que toda la siderurgia continental necesitaba suministros externos. Las posibilidades se reducían a Vizcaya, Santander, Penibética, región sueca de Laponia y Lokris, en Grecia. De estas cuencas, la de Somorrostro presentaba las mejores condiciones de oferta. Sus minerales eran ricos y puros. Sus reservas -más de 200 millones de toneladas métricas cubicadas - restaban riesgos a las inversiones. Podían laborearse a cielo abierto y distaban escasos kilómetros del mar, factores ambos que aseguraban bajos costes de extracción y de transporte ${ }^{3}$.

A estas ventajas naturales se sumó la promulgación de una legislación liberal que abolió antiguas rémoras institucionales tales como el retorno de las minas al Estado en caso de no ser laboreadas, los elevados derechos de exportación y las trabas a la libre constitución y funcionamiento de las sociedades anónimas. La Ley minera de 1868 eliminó el primer obstáculo al establecer firmes derechos de propiedad sobre las concesiones. La franquicia de exportación data de 1863 y la Ley de Sociedades de 1869

${ }^{1}$ En 1868, la tonelada de mineral de Cumberland costaba 12 chelines, mientras que en 1873 pasó a valer 30 chelines y 6 peniques. Ello hizo que el lingote hematites pasara de 60 chelines y 4 peniques en el primer año a $155 / 6$ en 1873. Por su parte, los raíles de acero pasaron de 5 libras y 12 chelines a 15 libras y 10 chelines. Los precios proceden de Carr-Taplin (1962), p. 85.

${ }^{2}$ Este hecho fue destacado por Flinn (1955) en un trabajo pionero sobre las inversiones inglesas en el hierro español.

${ }^{3}$ Los minerales santanderinos eran similares a los vascos, pero mucho menos abundantes. Lo mismo sucedía con los penibéticos, que, además, presentaban el inconveniente de situarse lejos de la costa. Los criaderos suecos de Laponia tenían grandes reservas, pero un 80 por 100 eran fosforosas. El otro 20 por 100 eran menos ricas y puras. Ello no obstante, distaban $150 \mathrm{Km}$ del mar. Por su parte, la cuenca de Lokris disponía de pequeñas reservas. 
incluyó a las mineras entre las que podían constituirse sin previa autorización gubernamental y con ausencia de inspección en su funcionamiento. Siendo, pues, ineludible recurrir al criadero vizcaíno, la siderurgia europea tenía dos opciones: comprar los minerales a las empresas que explotaran los yacimientos o bien crear sociedades integradas verticalmente con sus factorías.

La primera estrategia presentaba la ventaja de no incurrir en los riesgos inherentes a toda inversión, más y cuando España atravesaba un proceso de grave inestabilidad política. Sin embargo, acudir al mercado comportaba dos incertidumbres de largo plazo. En primer lugar, las fluctuaciones alcistas de los precios. Luego, unos costes de transacción susceptibles de encarecer las menas o de comprometer la regularidad de los suministros. Se trataba de costes de información (precios relevantes, proveedores, calidades...), de costes de negociación (elevado número de contratos) y de costes de garantía (falibilidad y/o comportamiento oportunista de múltiples productores o intermediarios que pudieran hacer peligrar los aprovisionamientos) ${ }^{4}$.

A estas incertidumbres de largo plazo se añadió un problema coyuntural. Entre 1870 y 1875 , sólo existió el ferrocarril minero de Triano, propiedad de la Diputación, ya que otro cuya concesión consiguieron los Ibarra en 1872 no pudo construirse por el estallido de la guerra carlista ${ }^{5}$. El ferrocarril tenía entonces una capacidad de acarreo de unas 500.000 toneladas por año. Ello obstruía la oferta, de manera que este problema debió de pesar

4 La integración vertical ha recibido lecturas estratégicas, tecnológicas y de economía de los costes de transacción. La primera hipótesis posee una capacidad explicativa limitada, ya que la integración vertical ha buscado preferentemente la eficiencia ante mercados imperfectos y no la creación de barreras de entrada a competidores. La explicación neoclásica también resulta insuficiente porque la tecnología delimita los modos de organización viables, pero no la elección final, que dependerá de la diferencia entre los costes de transacción y los de organización interna. Las distintas hipótesis sobre la integración vertical en Williamson (1989a, capítulo IV) y en Perry (1989, pp. 187-188). Estudios de la integración vertical desde la óptica de la economía de los costes de transacción son, entre otros, los de Klein, Crawford y Alchian (1978), Williamson (1971, 1989a, 1989b), Chandler (1988, 1996), Perry (1989) y Lazonick (1991). En el caso español, y también desde la óptica del ahorro de costes de transacción, Torres Villanueva (1993) ha estudiado la estrategia y estructura del grupo Sota y Aznar, y Rosés (1997) la integración vertical en el sector algodonero catalán.

'Sé de la existencia de esa concesión ferroviaria por un trabajo inédito probablemente escrito por Lazurtegui (Anónimo, 1921) que he hallado en su archivo y por un libro de Montero (1990, pp. 111 y 133). El ferrocarril debía unir la zona del Regato con el Nervión. Los Ibarra buscaban conectar sus minas con la ría y con sus fábricas de El Carmen y de Guriezo, así como alquilar el servicio a los demás mineros de la zona. Lazurtegui afirma que el ferrocarril no se pudo construir por el estallido de la guerra carlista. 
en la estrategia de las empresas que decidieron no recurrir al mercado. De hecho, el cónsul británico en Bilbao escribía en 1871:

«It is much to be regrettet that the parties in England interested in the export of iron ore from Bilbao did not adopt proper measures to ascertain from independent reliable sources the real conditions of the port, previously to entering into vast contracts for the supply of that material (...). These important considerations appear to have been entirely overlooked (...) and the port has been blocked with ships, chiefly French and English, chartered to carry out in the course of a few months contracts which are stated to have been made for upwards of one million tons of ore, when the utmost quantity which at present, and for some time to come, could be loaded, would not exceed a rate of 500.000 tons per annum» 6 .

La segunda estrategia presentaba el riesgo de invertir en un país políticamente inestable. Se requerían, además, fuertes sumas para montar ferrocarriles y comprar buques porque las concentraciones verticales logran mayores economías de escala cuando conectan sus unidades operativas por medios de transporte propios capaces de asegurar flujos baratos y regulares. La estrategia ofrecía, sin embargo, grandes ventajas. En el corto plazo, solucionar el problema coyuntural antes descrito. En el largo plazo, explotar los ferrocarriles acarreando mena ajena, pero, sobre todo, eliminar costes de transacción o, lo que es lo mismo, comprar minerales a precios inferiores a los de mercado garantizando también un suministro regular que no quebrara la escala de producción ${ }^{7}$. Prescindir del mercado presentaba, pues, la ventaja de fabricar un acero más competitivo.

La historia del sector demuestra que fue el tamaño de las empresas siderúrgicas lo que determinó el empleo de una u otra estrategia. Algunos de los gigantes de la época (Brown, Fowler, Bolckow Vaughan, Consett, Dowlais, Krupp, Cockerill, Denain et Anzin y Montataire) concentraron verticalmente grandes cotos mineros con sus fábricas porque poseían recursos para invertir y directivos para negociar en Vizcaya; porque tenían la experiencia previa de haber absorbido minas domésticas y también porque la especificidad de los convertidores Bessemer y el tamaño e

- Parlamentary Papers Reports (1871, p. 174).

${ }^{7}$ En sus trabajos sobre los procesos de concentración vertical, Chandler y Lazonick han destacado que las economías de escala dependen tanto de la capacidad productiva instalada como de las economías de velocidad (flujo barato y regular de inputs). Si ese flujo es caro y menor que la capacidad, los costes medios aumentan, sobre todo en industrias organizadas en grandes plantas como la siderurgia. Chandler (1988, pp. 392 y ss.), Chandler (1996, pp. 38 y 61), Lazonick (1991, pp. 132 y ss.). 
integración de sus plantas (cockerías, altos hornos, acerías, laminados) creaban incentivos para ello ${ }^{8}$. En cambio, las pequeñas y fragmentadas fundiciones y acerías británicas recurrieron al mercado ${ }^{9}$.

Concentrar verticalmente las minas exigía una última decisión: hacerlo individualmente o bien optar por la cooperación -esto es, crear entre varias compañías siderúrgicas una sociedad filial concertando los cupos de mena a recibir por cada socio-. Ambas opciones desembocaban en flujos baratos y regulares. Sin embargo, la primera comportaba una fuerte inversión en el ferrocarril y grandes pérdidas de fracasar la empresa. Por el contrario, el «árbol» de la segunda decisión conducía a menores inversiones y pérdidas. Tres de las cuatro integraciones verticales creadas en Vizcaya (Bilbao Iron Ore, Orconera y Franco Belga) tomaron la forma de alianza estratégica - no así la Luchana Mining-. De ello se deduce que la mayoría de las empresas siderúrgicas calibraron como superiores los beneficios de la cooperación. Por otro lado, las negociaciones que precedieron a la creación de la Orconera demuestran que el factor clave de esa decisión fue prorratear el coste de los ferrocarriles ${ }^{10}$.

Como se verá más adelante, las cuatro empresas suministraban a sus fundadores mineral a precios preferenciales inferiores a los de mercado. Ello les proporcionaba cortos beneficios por tonelada. Sin embargo, como su volumen de ventas era grande y acarreaban mineral ajeno en sus ferrocarriles, los beneficios totales permitían correr con los gastos de amortización, nuevas inversiones, pago de impuestos y reparto de dividendos, de manera que las casas siderúrgicas obtenían una doble utilidad. La más importante, disponer de un suministro regular de mena

${ }^{8}$ La existencia de activos específicos es, según Williamson (1989a, cap. IV), un factor clave de la integración vertical, ya que cuanto menor sea el uso alternativo de los activos, mayor será el incentivo para evitar el oportunismo en las transacciones efectuadas con otras empresas. Por su parte, Chandler (1996, pp. 60-61) ha hecho especial hincapié en que cuanto mayor sea la inversión en medios intensivos en capital y mayor la dimensión de éstos, mayor será el incentivo para asegurarse frente a costes de transacción.

9 Frente a la hipótesis tradicional que vinculaba el climaterio de la siderurgia inglesa al predominio de la tecnología ácida, McClosckey (1973) y Elbaum (1986), entre otros, han demostrado que ese climaterio provino del pequeño tamaño y del escaso grado de concentración vertical y horizontal de la industria.

${ }^{10} \mathrm{La}$ Consett y la Dowlais entraron primero en contacto con la Bolckow Vaughan y con John Brown para que se unieran a la empresa con el fin de compartir unas inversiones sólo cuantiosas por el lado de los medios de transporte -de hecho, esta partida absorbió el 85 por 100 de las inversiones de la Orconera-. Ambas casas siderúrgicas declinaron la oferta, ya que previamente habían creado la Bilbao Iron Ore y la Luchana Mining. Fue entonces cuando se entró en contacto con la Krupp, que sí que aceptó entrar en Orconera. Wengenroth (1984), p. 7. 
barata. Luego, obtener ganancias de sus filiales. La Franco Belga, la Bilbao Iron Ore y la Luchana Mining nunca vendieron en el mercado libre. Por el contrario, los estatutos de la Orconera contemplaban la posibilidad de comercializar excedentes a precios de mercado, probablemente por las grandes reservas de su coto.

El siguiente cuadro muestra la diferencia entre los precios de mercado y los precios preferenciales a los que la Orconera y la Franco Belga compraron sus menas entre 1876 y 1913 :

\section{CUADRO 1}

Precios de mercado y precios preferenciales f.o.b. del mineral de bierro vizcaino (1876-1913)

(pesetas por $\mathrm{Tm}$ )

\begin{tabular}{|c|c|c|}
\hline Período & $\begin{array}{l}\text { A. Precios } \\
\text { de mercado* }\end{array}$ & $\begin{array}{c}\text { B. Precios } \\
\text { preferenciales * }\end{array}$ \\
\hline 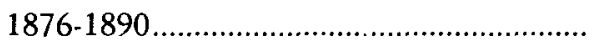 & 8,8 & 6 \\
\hline 1891-1900 & 11 & 7 \\
\hline $1901-1913$ & 16,7 & 9,3 \\
\hline
\end{tabular}

* Los precios de mercado son la media de los del período y proceden de la Revista Minera. Los preferenciales resultan de sumar 2 pesetas a los costes medios de la Orconera y de la Franco Belga (infra, cuadros 6 y 12), ya que estas empresas vendían a sus casas fundadoras cada tonelada a unas 2 pesetas sobre el coste unitario.

Se observa que, entre 1876 y 1900 , las fábricas dueñas de las dos empresas compraron minerales un 34 por 100 más baratos que los de mercado. Esa diferencia alcanzó el 44 por 100 entre principios de siglo y la Primera Guerra Mundial porque la fase A del Kondratieff 1897-1933 elevó mucho la demanda de menas. Los precios evidencian que la integración vertical fue en este caso más eficiente que el mercado.

\section{EMPRESAS VIZCAÍNAS CONCENTRADAS VERTICALMENTE CON LA SIDERURGIA EUROPEA}

La primera de ellas fue la Bilbao Iron Ore, constituida en 1871 con un capital de 500.000 libras suscrito por dos de los más importantes fabricantes de acero de Sheffield, John Brown y William Fowler ${ }^{11}$. Ambas

${ }^{11}$ Contienen información sobre esta empresa los trabajos de Flinn (1952), pp. 138-139; Broder (1981), pp. 1610-1612; Wengenroth (1984), pp. 6-7, y Chastagnaret (1985a), p. 738. 
compañías entraron en contacto con J. Ochandiano, propietario de un coto de $127 \mathrm{Ha}$. sito en Galdames y formado por las minas Berango, Cenefa, Tardía y Escarpada ${ }^{12}$. Ochandiano transfirió los derechos de propiedad del coto a la Bilbao Iron Ore a cambio de recibir acciones por valor de 5.000 libras $^{13}$. En 1876, la empresa terminó la preparación de labores y la construcción de un ferrocarril de 22 kilómetros con cuatro cargaderos. El coste de todo ello ascendió a 17,5 millones de pesetas, una cifra más elevada de la que luego invirtieron la Luchana, la Orconera y la Franco Belga, ya que el ferrocarril de Galdames tenía un «largo» recorrido y las obras se vieron encarecidas por un terreno especialmente abrupto ${ }^{14}$. Como la inversión superó al capital originario, la empresa emitió obligaciones por un valor de 150.000 libras ${ }^{15}$.

Entre 1876 y 1882, la Bilbao Iron Ore produjo de 100 a $150.000 \mathrm{Tm}$ por año que vendió a sus socios fundadores a precios preferenciales, cuya cuantía ignoro ${ }^{16}$. La sociedad abandonó el laboreo en 1883 arrendando sus minas primero a la Vizcaya y luego a Altos Hornos de Vizcaya a cambio de un canon de 0,5 pesetas por tonelada arrancada ${ }^{17}$. Desde entonces, se dedicó sólo a la explotación de su ferrocarril, cambiando su nombre por el de Bilbao River and Cantabrian Railway Co. Ltd. ${ }^{18}$.

El diagrama A muestra el tonelaje acarreado por el ferrocarril de la compañía. Aparecen dos grandes períodos que se corresponden con los ciclos expansivo y depresivo del sector. El primero (1876-1913) fue consecuencia de la fidelidad del Reino Unido a los sistemas siderúrgicos ácidos y de la consiguiente inelasticidad de la demanda inglesa hacia los minerales vascos dada la insuficiente oferta de inputs sustitutivos —otras menas sin fósforo y chatarra sin esta impureza- ${ }^{19}$. El ciclo depresivo (1914-1936) arrancó del cambio tecnológico efectuado por la siderurgia

${ }^{12}$ Ochandiano aparece como propietario del coto en el Catastro Minero de 1909. Estadística Minera de ese año.

${ }^{13}$ Broder (1981), p. 1610.

14 El ferrocarril de la Luchana tenía $12,2 \mathrm{Km}$. El de la Orconera, 18,9, y el de la Franco Belga, 8,9. Goenaga (1883).

is Broder (1981), p. 1610.

16 En Anónimo (1921) se dice que la empresa proporcionaba mineral a dos casas de Sheffield dueñas de la misma, pero no se especifica a qué precios. La producción de la empresa procede de los Censos del Círculo Minero (ACM).

17 Monografia de Altos Hornos de Vizcaya de 1909 (p. 16). Las contabilidades de la Vizcaya y de Altos Hornos de Vizcaya asientan el canon de 0,5 en sus pasivos.

${ }_{18}$ Flinn (1952), p. 139. Wengenroth (1981), p. 6.

${ }^{19}$ Es sabido que los sistemas ácidos son aquellos que consumen inputs sin fósforo, esto es, el Bessemer, que beneficia arrabio obtenido de menas puras, y el Martin Siemens con revestimiento ácido, que beneficia arrabio sin fósforo y chatarra sin esta impureza. 


\section{DIAGRAMA A}

Mineral transportado por la Bilbao River (1876-1935)

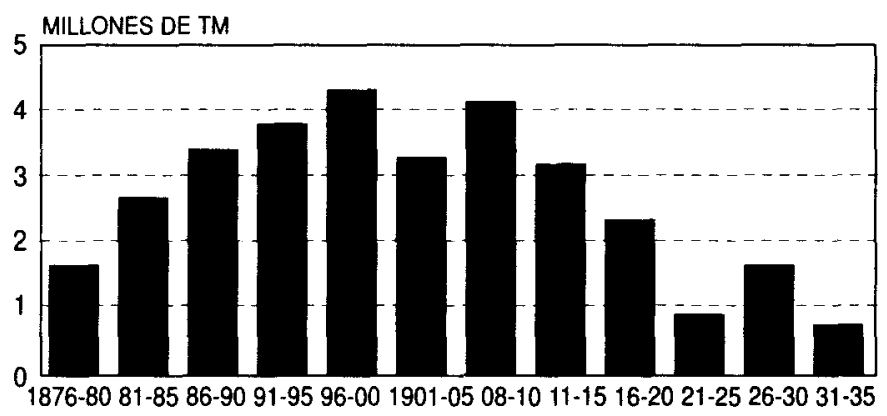

Fuentes: 1876-1900: Anónimo (1921). AJL. 1901-1936: Cuentas de resultados del Ferrocarril de la Bilbao River. AAD.

británica durante la Gran Guerra. El encarecimiento de los fletes hizo que las fábricas montaran hornos Martin Siemens básicos capaces de beneficiar cualquier tipo de arrabio y de chatarra. Después de 1921, el desplome de los precios de ésta hundió la demanda de lingote y de minerales ${ }^{20}$.

En el diagrama B aparecen las tarifas medias del ferrocarril de Triano y las del Bilbao River. Se observa que éstas fueron sustancialmente mayores (por ejemplo, 3,25-3,75 pesetas entre 1883 y 1900 frente a $1,81-2,16$ ). El hecho no puede atribuirse a longitudes distintas, ya que el ferrocarril de la Diputación tenía $20 \mathrm{Km}$ y el de la compañía inglesa 22 , de manera que no queda otra explicación que la del oligopolio de transporte. La Bilbao River, la Orconera, la Franco Belga y la Luchana fijaron precios de monopolio al mineral ajeno que acarrearon porque sus clientes no podían transportar las menas por otros medios. Si el ferrocarril de la Diputación no actuó del mismo modo fue por su carácter de empresa pública ${ }^{21}$.

El cuadro 2 contiene los beneficios de la Bilbao River en algunos años del ciclo expansivo y después de la Primera Guerra Mundial. La primera serie arroja ganancias unitarias de unas 1,7 pesetas, de manera que,

${ }^{20} \mathrm{He}$ estudiado esos ciclos en mi libro Minería e industrialización de Vizcaya (Ed. Grijalbo, en prensa).

${ }^{21}$ La patronal minera visitó en distintas ocasiones al Presidente de la Diputación y a los gerentes de las empresas con ferrocarril para solicitar menores tarifas. El resultado de las conversaciones siempre fue el mismo: transigencia en el primer caso e inflexibilidad en el segundo. Libros de Actas del Círculo Minero y de la Cámara Minera (ACM y ACAM). 
DIAGRAMA B

Tarifas ferrocarriles Triano y Bilbao River (1876-1936)

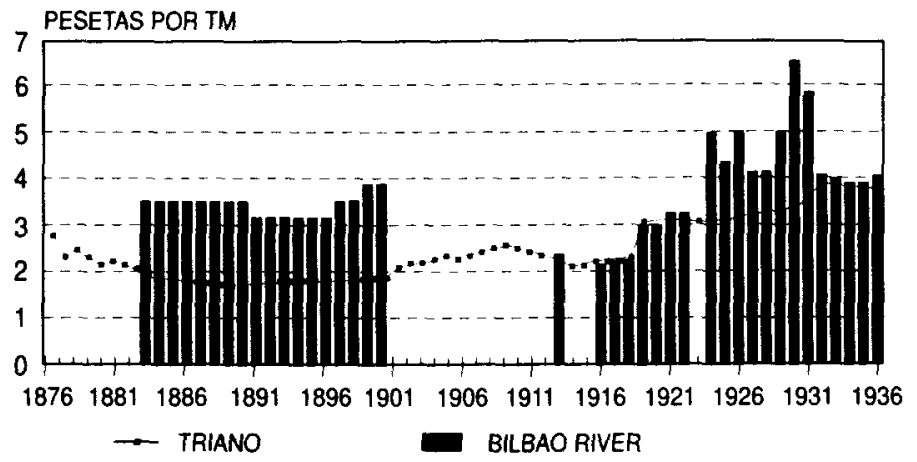

FuENTES: Triano: AAD. Carpeta 480. Legajos 1.622/3. Bilbao River: 1883-1900: Gandolfi (1888) y González Portilla (1985). 1901-1936; Cuentas de Resultados del ferrocarril de la Bilbao River. $A A D$. La tarifa media es el resultado de dividir los ingresos por el tonelaje acarreado.

multiplicando el tonelaje acarreado por la compañía entre 1880 y 1913 por esa cantidad, obtenemos sus beneficios verosímiles. Esto es, 43 millones (25,4 millones de $\mathrm{Tm} \times 1,7$ pesetas). A tenor de los datos aportados por Harvey y Taylor, la empresa reinvirtió muy pocas ganancias, ya que, entre 1871 y 1913, repartió dividendos por un valor de 1,4 millones de libras ${ }^{22}$.

\section{CUADRO 2}

Ferrocarril de la Bilbao River and Cantabrian Railway.

Tonelaje, beneficios y beneficio medio (1880-1936)

\begin{tabular}{|c|c|c|c|}
\hline Años & $\begin{array}{c}\text { Tonelaje } \\
\text { (miles de } \mathrm{Tm} \text { ) }\end{array}$ & $\begin{array}{c}\text { Beneficios } \\
\text { (miles de pesetas) }\end{array}$ & $\begin{array}{l}\text { Beneficio medio } \\
\text { (pesetas) }\end{array}$ \\
\hline 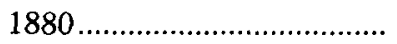 & - & 818 & - \\
\hline 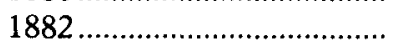 & - & 1.040 & - \\
\hline 1883 & 810 & 1.042 & 1,28 \\
\hline 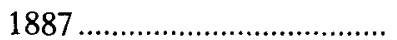 & 998 & 1.715 & 1,71 \\
\hline 1888 & 861 & 1.668 & 1,93 \\
\hline
\end{tabular}

22 Harvey-Taylor (1987), p. 195. 


\begin{tabular}{|c|c|c|c|}
\hline Años & $\begin{array}{c}\text { Tonelaje } \\
\text { (miles de Tm) }\end{array}$ & $\begin{array}{c}\text { Beneficios } \\
\text { (miles de pesetas) }\end{array}$ & $\begin{array}{c}\text { Beneficio medio } \\
\text { (pesetas) }\end{array}$ \\
\hline 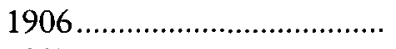 & 964 & 1.688 & 1,73 \\
\hline 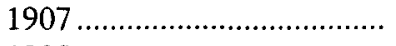 & 852 & 1.379 & 1,61 \\
\hline 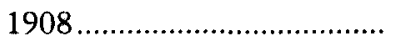 & 824 & 1.393 & 1,69 \\
\hline 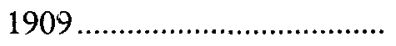 & 827 & 1.363 & 1,64 \\
\hline 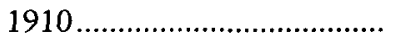 & 795 & 1.763 & 2,21 \\
\hline 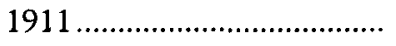 & 765 & 1.350 & 1,74 \\
\hline $1913 \ldots \ldots \ldots \ldots$ & 727 & 1.052 & 1,4 \\
\hline 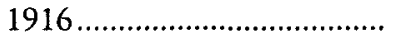 & 625 & 201 & 0,3 \\
\hline 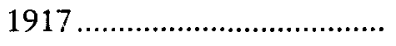 & 535 & 92 & 0,1 \\
\hline $1918 \ldots \ldots \ldots \ldots$ & 599 & 114 & - \\
\hline 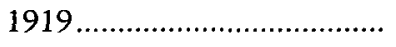 & 243 & -206 & - \\
\hline 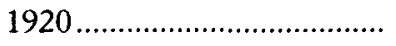 & 322 & -379 & - \\
\hline 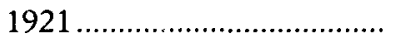 & 150 & -453 & - \\
\hline 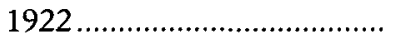 & 123 & -344 & - \\
\hline 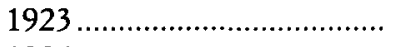 & 211 & - & 一 \\
\hline 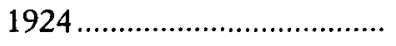 & 222 & 13 & 0,05 \\
\hline 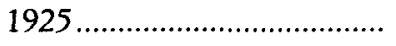 & 238 & 11 & 0,05 \\
\hline 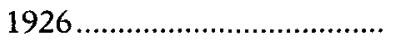 & 110 & -203 & - \\
\hline 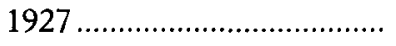 & 161 & 36 & 0,2 \\
\hline 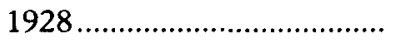 & 239 & 134 & 0,5 \\
\hline 1929 & 294 & 422 & 1,4 \\
\hline 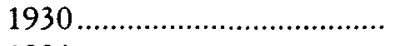 & 197 & -44 & 一 \\
\hline 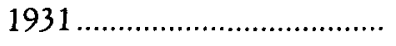 & 196 & -68 & - \\
\hline 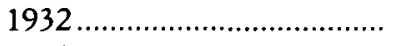 & 176 & -55 & - \\
\hline 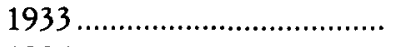 & 122 & -50 & - \\
\hline 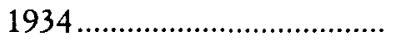 & 133 & -12 & - \\
\hline 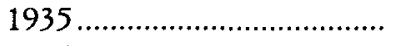 & 121 & 42 & 0,3 \\
\hline 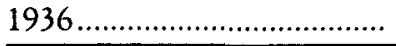 & 101 & 26 & 0,2 \\
\hline
\end{tabular}

FUENTES: Tonelaje: 1880-1921 (Anónimo, 1921); 1922-1936 (Cuentas de resultados de la Bilbao River, AAD). Beneficios: 1880-1888 (Broder, 1981, p. 1612); 1906-1911 (Estadísticas de la Contribución sobre utilidades de la Riqueza Mobiliaria); 1913-1920 (Anuario Riu); 1921-1936 (Cuentas de resultados de la Bilbao River. AAD).

En 1900, el Círculo Minero decía: «Seguramente, el ferrocarril de Triano será el que baya conseguido mayores rendimientos en Europa y Américas ${ }^{23}$. Pues bien, el siguiente cuadro demuestra que, dada la situación oligopolística antes descrita, el de la Bilbao River alcanzó mayores beneficios unitarios:

${ }^{23}$ Las minas de hierro de la provincia de Vizcaya, Círculo Minero, Bilbao, 1900, p. 92. 


\section{CUADRO 3}

Beneficios medios de los ferrocarriles de Triano y Bilbao River (pesetas por $\mathrm{Tm}$ )

\begin{tabular}{|c|c|c|}
\hline Años & Triano & Bilbao River \\
\hline 1883 & 1,05 & 1,28 \\
\hline 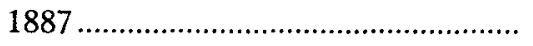 & 1,18 & 1,71 \\
\hline 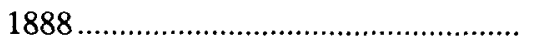 & 1,12 & 1,93 \\
\hline 1906 & 1,05 & 1,73 \\
\hline 1907 & 0,99 & 1,61 \\
\hline 1908 & 0,94 & 1,69 \\
\hline 1909 & 0,98 & 1,64 \\
\hline 1910 & 0,94 & 2,21 \\
\hline 1911 & 0,86 & 1,74 \\
\hline 1913 & 0,54 & 1,44 \\
\hline
\end{tabular}

FUENTES: Bilbao River, las citadas en el cuadro 1. Triano: Cuentas de resultados (AAD).

Como puede observarse en el cuadro 2, el ferrocarril arrojó pérdidas en once de los veintidós años del ciclo depresivo del sector, siendo sus ganancias muy pequeñas en los demás ejercicios. Ello fue consecuencia del desplome de la demanda de minerales, que arrastró consigo a la demanda derivada de transporte, haciendo que los ingresos del ferrocarril se hundieran. Simultáneamente, los costes crecieron al acarrearse un menor tonelaje y al aumentar los salarios y los precios del carbón ${ }^{24}$. Tras la guerra civil, el ferrocarril fue comprado por la Babcock and Wilcox.

La información que poseo sobre la segunda de las empresas concentradas verticalmente con la siderurgia europea es escasa. La Luchana Mining se creó en 1871 ó 1872 con un capital de 150.000 libras desembolsadas por la más importante fábrica de acero inglesa, la Bolckow Vaughan ${ }^{25}$. La sociedad registró un coto de $67 \mathrm{Ha}$. e inició la construcción de un ferrocarril de $12,2 \mathrm{Km}$ tras la guerra carlista, pero, por razones que ignoro, no lo terminó hasta 1887 . El coste de las obras ascendió a 1.335 .000 pesetas (881.000 el ferrocarril y 474.000 el embarcadero) ${ }^{26}$. La Luchana arrendó sus concesiones a Castaños entre 1884 y 1897,

${ }^{24}$ Los ingresos y gastos del ferrocarril en Escudero (en prensa).

${ }^{25}$ Información sobre esta empresa en Anónimo (1921); Flinn (1952), p. 318; Wengenroth (1984), p. 23, y Chastagnaret (1985a), p. 738. Wengenroth dice que no está claro en los registros si la empresa se creó en 1871 ó 1872.

${ }^{26}$ Echevarría (1900), p. 6. 
dedicándose sólo a la explotación de su ferrocarril ${ }^{27}$. Luego comenzó el laboreo extrayendo cantidades cercanas a las $100.000 \mathrm{Tm}$ anuales para los altos hornos de la Bolckow ${ }^{28}$. El mineral era embarcado en buques de la propia fábrica inglesa ${ }^{29}$. Entre 1888 y 1913, el ferrocarril transportó 5,4 millones de Tm ajenas, de manera que, asignándole beneficios unitarios de 1,5 pesetas, sus ganancias en ese período debieron de ascender a unos 8 millones ${ }^{30}$. La Luchana fue adquirida por Altos Hornos de Vizcaya en $1927^{31}$.

La información sobre la tercera de las empresas objeto de estudio es más abundante. La Orconera Iron Ore se constituyó en Londres en 1873 con un capital de 200.000 libras, representado por 400 acciones de 500 libras cada una ${ }^{32}$. Los fundadores fueron los Ibarra y dos grandes casas siderúrgicas británicas, la Consett, sita en Cardiff, y la Dowlais, sita en Durham ${ }^{33}$. Estos primeros socios entablaron conversaciones con la Brown y con la Bolckow para que ingresaran en la Orconera, pero ambas desestimaron la oferta, ya que previamente habían creado la Bilbao Iron Ore y la Luchana Mining. Fue entonces cuando optaron por invitar a la Krupp. La compañía alemana había renunciado unos años antes a un proyecto poco conocido: instalar en el Nervión altos hornos para autoabastecerse de lingote sin fósforo. La iniciativa no se materializó porque los aranceles sobre el coque a importar desde Alemania encarecían los costes en Bilbao igualándolos con los de los altos hornos de Duisberg y Essen y porque se consideró difícilmente transferible el nivel tecnológico alcanzado en estas factorías ${ }^{34}$. La Krupp aceptó entonces la oferta. Según Lazurtegui, el capital se repartió del siguiente modo:

- Krupp

- Dowlais Co. of South Wales.

- Consett Co. of Durham

- Ibarra H. ${ }^{\text {os }}$ y Cosme Zubiría.
115 acciones ( $28,7 \%$ del capital)

115 acciones $(28,7 \%$ del capital)

114 acciones ( $28,5 \%$ del capital) 56 acciones (14\% del capital) ${ }^{35}$

${ }^{27}$ Durante estos años, los Censos del Círculo Minero citan a Castaños como explotador del coto de la Luchana.

${ }^{28}$ La producción procede de los Censos del Círculo Minero de Bilbao.

29 Wengenroth (1984), nota 13, p. 24.

${ }^{30}$ En Anónimo (1921) se dice que las empresas extranjeras con ferrocarril obtenían beneficios medios de 1,5 a 2 pesetas, cifras que concuerdan con las ganancias de la Bilbao River.

${ }^{31}$ Memoria de Altos Hornos de Vizcaya, 1928.

${ }^{32}$ Lazurtegui ( $\sin$ fecha), p. 15.

33 Richardson y Bass (1965), p. 83. También Broder (1981), p. 1606.

34 Wengenroth (1984), pp. 10 y 11 , y notas 33 y 34.

${ }^{35}$ Lazurtegui (sin fecha), p. 16. 
La Krupp y la empresa minera pleitearon tras la Primera Guerra Mundial, ya que las autoridades británicas anularon en 1914 el contrato por el que la Orconera proporcionaba mena a la casa alemana. Ésta llevó el asunto a los tribunales españoles alegando incautación de cupos. La Audiencia de Burgos condenó a la Orconera a entregar a la Krupp el mineral no recibido durante la contienda, pero el Tribunal Supremo falló a favor de aquélla ${ }^{36}$. Ello hizo que la Krupp la abandonara en 1919. La sociedad amplió entonces capital a 2 millones de libras dada la necesidad de mecanizar el laboreo. Ésta fue la nueva distribución:

- Consett $750.000(37,5 \%$ del capital $)$

- Dowlais $750.000(37,5 \%$ del capital $)$

- Ibarra Hermanos 500.000 (25,0\% del capital) ${ }^{37}$.

La Orconera se creó para explotar durante noventa y nueve años minas de los Ibarra, un coto de $400 \mathrm{Ha}$. situado en la zona más rica del criadero, entre el Regato y el río de Somorrostro ${ }^{38}$. Se concertó un canon de arrendamiento de 8 peniques por tonelada y los Ibarra transfirieron a la empresa la concesión ferroviaria a la que antes me referí ${ }^{39}$. El mineral era vendido a los fundadores en forma de cupos y a un precio preferencial de 1 chelín y 7 peniques la tonelada sobre el coste, aunque también podían comercializarse excedentes a precios de mercado ${ }^{40}$. Los lotes convenidos en 1873 fueron de $100.000 \mathrm{Tm}$ por socio y año. La Krupp y la Dowlais incrementaron sus cuotas a $200.000 \mathrm{Tm}$ desde 1876 , ya que aportaron más recursos a la compañía para que ésta afrontara unos gastos que superaban el capital desembolsado ${ }^{41}$. No hubo, pues, ni ampliación de capital ni reestructuración del primitivo al contentarse ambos socios con recibir el doble de mena a precios preferenciales ${ }^{42}$. El cupo correspondiente a los Ibarra y Zubiría fue traspasado por éstos a Altos Hornos de Bilbao en 1882 a cambio de una prima de 0,5 pesetas por tonelada de Orconera

\footnotetext{
36 «Pleito Orconera-Krupp», Boletín Minero (8-10-1928).

37 En el acta que la inspección de Hacienda levantó a la Orconera en 1927 se especifica que la empresa amplió capital en 1919 a 2 millones de libras con el reparto de capital arriba citado.

${ }^{38}$ S. F. (15-6-1926). Boletín Minero. Se trataba de un coto formado por las minas Mame, Carmen, Concha, César, Orconera, Previsión, Trinidad y Capela. Censos del Círculo Minero (ACM).

39 Montero (1990), p. 111.

40 Orconera (folleto de 1883).

${ }^{41}$ Orconera (folleto de 1883).

${ }^{42}$ Wengenroth (1984), p. 8.
} 
beneficiada en la fábrica ${ }^{43}$. La Dowlais, la Consett y la Krupp adquirieron buques que traían carbón al Atlántico francés y a Bilbao y embarcaban mena hacia Durham, Cardiff y Rotterdam ${ }^{44}$.

Proporcionar $600.000 \mathrm{Tm}$ anuales a sus accionistas exigió a la Orconera una fuerte inversión, sobre todo del lado de los medios de transporte (plano inclinado, ferrocarril y embarcadero, un 85 por 100 de la suma que aparece en el siguiente cuadro):

\section{CUADRO 4 \\ Capital invertido por la Orconera basta 1883}

\begin{tabular}{|c|c|}
\hline & Pesetas \\
\hline Ferrocarril & 6.856 .152 \\
\hline 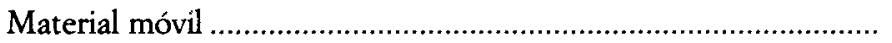 & 1.297 .608 \\
\hline 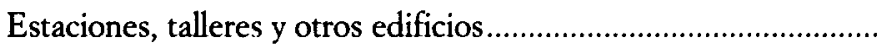 & 317.472 \\
\hline Maquinaria para reparaciones. & 64.632 \\
\hline 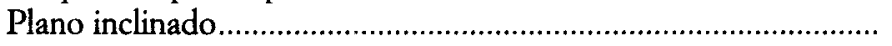 & 704.496 \\
\hline Vías, maquinaria & 293.256 \\
\hline 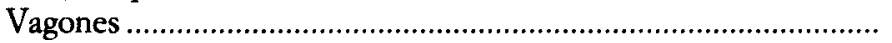 & 147.312 \\
\hline Embarcadero & 309.048 \\
\hline Trabajos preparación minas .................................................... & 1.148 .112 \\
\hline 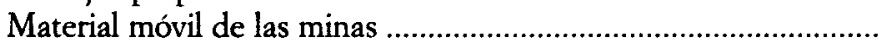 & 96.912 \\
\hline 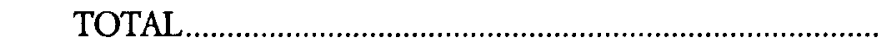 & 11.235 .000 \\
\hline
\end{tabular}

FUENTE: Orconera Iron Ore (folleto de 1883).

La inversión fue muy superior al capital desembolsado (200.000 libras, unos 5 millones de pesetas al cambio). La sociedad hizo frente a la situación mediante un triple procedimiento. En primer lugar, con la citada inyección de capital de la Krupp y de la Dowlais. En segundo lugar, endeudándose con una emisión de 30.000 obligaciones por valor de 150.000 libras a un interés del 7 por 100 que amortizó en $1888^{45}$. Luego, mediante una política de acumular importantes fondos de reserva durante la década de los ochenta ${ }^{46}$.

${ }^{43}$ Conozco este dato gracias a Fernández de Pinedo, que ha descubierto en el Archivo de Protocolos el contrato entre los Ibarra y la Orconera.

${ }^{44}$ Anónimo (1921). AJL.

${ }^{45}$ Broder (1981), p. 1606.

46 Wengenroth (1984), pp. 8 y 9 , y nota 24 . En 1883 , por ejemplo, la empresa disponía de 197.359 libras de reservas no distribuidas. 
Desde entonces y hasta 1920 , la compañía realizó una sola inversión de envergadura. A principios de siglo -y como era preciso calcinar y lavar por el progresivo agotamiento de los rubios- gastó 6 millones de pesetas en la construcción de hornos y de trómeles, sitos éstos en Poveña y comunicados con las minas mediante un tranvía aéreo de 8.500 metros ${ }^{47}$. Huelga decir que, proyectada para explotar un gran coto, la maquinaria de la Orconera alcanzaba rendimientos mucho mayores que la de las otras empresas que laboreaban minas pequeñas y por lo general dispersas ${ }^{48}$.

Hasta la Primera Guerra Mundial, la cadena de producción fue ésta. Tras barrenar a brazo, se procedía a la voladura. Los peones troceaban con mazas los grandes bloques y seleccionaban manualmente los rubios y carbonatos según tamaños. Simultáneamente, otros jornaleros desescombreaban las tierras mineralizadas (chirtas) mediante rastrillos. Se procedía después a la carga a vagoneta con capazos. Los rubios eran transportados mediante plano inclinado a ferrocarril. Los carbonatos, a hornos de calcinar también en plano inclinado y luego a ferrocarril. Las chirtas se acarreaban mediante tranvía aéreo a los lavaderos y después a ferrocarril.

La empresa mecanizó el laboreo en la década de 1920. Este «atraso» requiere ser analizado desde una perspectiva técnica y otra económica ${ }^{49}$. Hasta fines del Xxx, el laboreo manual fue técnicamente eficiente, ya que no se habían perfeccionado ni los martillos perforadores ni las excavadoras a vapor, maquinaria que, además, presentaba el inconveniente de una escasa movilidad, así como de unos rendimientos imposibles de acoplar al troceo y selección dada la inexistencia de machacadoras. La situación cambió desde principios de siglo. El laboreo manual perdió eficiencia técnica por el agotamiento del criadero y la maquinaria se perfeccionó. Sin embargo, la Orconera no mecanizó entonces por razones económicas. Entre 1900 y 1913, los salarios resultaron más baratos que la maquinaria por la existencia de un amplio ejército de reserva, de manera que el proceso productivo continuó siendo intensivo en trabajo.

47 Balzola (15-9-1928).

48 Automotor y de doble efecto, el plano inclinado de la Orconera alcanzaba rendimientos de $2.500 \mathrm{Tm}$ diarias, mientras que los pequeños planos no superaban las 500 . El tranvía aéreo de la empresa podía transportar $2.700 \mathrm{Tm}$ por jornada y los demás de la cuenca no superaban las 1.000 . En cuanto a hornos y trómeles, los de la sociedad tenían, respectivamente, rendimientos de 70 y $200 \mathrm{Tm}$ por jornada, mientras que los medios de los del sector eran de 40 y 50 . Balzola (15-9-1928).

${ }_{49}$ Un más detenido estudio de la tardía y desigual mecanización de las minas de Vizcaya en Escudero (1992). 
Todo lo contrario ocurrió tras la Primera Guerra Mundial. La UGT y el Sindicato Comunista lograron aumentos salariales acompañados de un jornal mínimo por debajo del cual la patronal no pudo contratar mano de obra, circunstancia que coincidió con un abaratamiento de los precios de la maquinaria eléctrica. Bajo estas condiciones - y para continuar suministrando un input barato a sus socios-, la Orconera procedió a la mecanización. Martillos y excavadoras eléctricas fueron adquiridos en los años veinte para barrenar, trocear, desescombrear y cargar. Los trómeles también fueron electrificados y los hornos de calcinar lograron mayores economías mediante nuevos sistemas de ventilación. En 1927, la empresa mejoró sus embarcaderos construyendo una línea aérea de conexión entre los depósitos de La Requeta y las cintas de embarque, elevando el rendimiento de 1.600 a $2.500 \mathrm{Tm}$ diarias. La cadena se cerró en 1934 al instalar máquinas quebrantadoras para trocear y seleccionar por tamaños los rubios y carbonatos ${ }^{50}$.

Orconera fue la empresa con mayor producción de la cuenca:

\section{CUADRO 5}

Orconera. Producción de mineral (1878-1936)

\begin{tabular}{|c|c|c|}
\hline Años & $\begin{array}{c}\text { Media } \\
\text { (miles de Tm) }\end{array}$ & $\begin{array}{c}\text { Porcentaje } \\
\text { sobre la producción } \\
\text { vizcaina }\end{array}$ \\
\hline 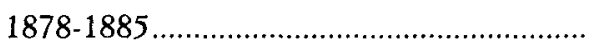 & 476 & 20,7 \\
\hline 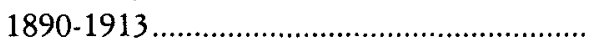 & 846 & 18 \\
\hline 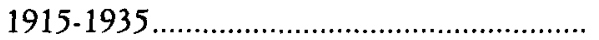 & 592 & 27 \\
\hline
\end{tabular}
(AAD).

FuENTE: Censos de producción del Círculo Minero (ACM) y Estadísticas de la Diputación

Entre 1876 y 1888 extrajo cantidades que correspondían a los cupos concertados con sus accionistas, de manera que todo el mineral fue adquirido por éstos a precios preferenciales. Desde 1889 a 1907 produjo un tonelaje superior. Esos excedentes (150.000-300.000 Tm por año) fueron vendidos a precios de mercado. La empresa volvió a extraer cantidades concertadas entre 1908 y 1920. Posteriormente - $-\mathrm{y}$ una vez

${ }^{50} \mathrm{He}$ obtenido esta información de las Memorias de la Orconera de los años 1920-1936 (AAD) y de varios números del Boletin Minero. 
que la Krupp la abandonara - continuó abasteciendo a sus socios con lotes preferenciales (Dowlais, 200.000 Tm; Consett, 200.000, y Altos Hornos de Vizcaya, 100.000). El resto del mineral lo vendió a precios de mercado.

La compañía siempre alcanzó una productividad superior a la del sector y laboreó con los menores costes f. o. b.:

\section{CUADRO 6}

Productividad y costes medios de la Orconera y del sector

\begin{tabular}{|c|c|c|c|c|c|c|}
\hline \multirow[b]{2}{*}{$A \bar{n} o s$} & \multicolumn{3}{|c|}{$\begin{array}{c}\text { Productividad } \\
\text { (kilos por obrero/bora) }\end{array}$} & \multicolumn{2}{|c|}{$\begin{array}{c}\text { Costes medios f. } o . b . \\
\text { (pesetas) }\end{array}$} & \multirow[b]{2}{*}{$\begin{array}{c}\text { Sector } \\
\text { (costes medios) }\end{array}$} \\
\hline & Orconera & Sector & Orconera & $\begin{array}{c}\text { Grandes } \\
\text { empresas } \\
\text { vascas }\end{array}$ & $\begin{array}{l}\text { Medianas } \\
\text { y pequeñas }\end{array}$ & \\
\hline $1890 \ldots \ldots \ldots \ldots$ & 217 & 168 & 4 & 5,2 & 7 & 5,3 \\
\hline $1897 \ldots \ldots \ldots \ldots$ & 201 & 180 & 5 & 6,5 & 8 & 6,3 \\
\hline $1912 \ldots \ldots \ldots \ldots$ & 158 & 133 & 7,4 & 9 & 12 & 10,3 \\
\hline $1913 \ldots \ldots \ldots \ldots$ & 155 & 130 & 7,3 & 9 & 12 & 10,3 \\
\hline $1925 \ldots \ldots \ldots \ldots$ & 190 & 153 & 16,6 & - & - & 17,99 \\
\hline $1930 \ldots \ldots \ldots \ldots$ & 177 & 149 & 15,6 & - & - & 18,1 \\
\hline $1936 \ldots \ldots \ldots \ldots$ & 297 & 129 & 14,9 & - & - & 19,7 \\
\hline
\end{tabular}

Fuentes: Productividad: Censos del Círculo Minero (ADM), «Preguntas dirigidas a los dueños, explotadores y contratistas de las minas de Vizcaya» (AAPM) y Estadísticas de la producción de mineral de la Diputación (AAD). Costes: 1890 y 1897: «Exposición del Círculo Minero al Ministro de Hacienda» (1890) (ACM); «Exposición al Ministro de Hacienda» (1896) (ACM); Gill (1892) y Anónimo (1921). Los costes de la Orconera de 1912 y 1913 los he obtenido restando a sus precios preferenciales 1 chelín y 7 peniques al cambio. Para los precios preferenciales, Wengenroth (1984), p. 8, y de sin firma: «Orconera», Boletín Minero (15-6-1926). Los costes de las demás empress antes de 1921 en Anónimo (1921). Los del período 1922-1936 proceden de la información elaborada por la Cámara Minera de Vizcaya (ACAM).

Los menores costes no sólo derivaban de su mayor productividad en la fase de laboreo. Como indica el siguiente cuadro, el hecho de que la compañía transportara en medios propios significaba un importante ahorro frente a las tarifas de mercado: 


\section{CUADRO 7}

\section{Costes del transporte del mineral vizcaino (pesetas por $\mathrm{Tm}$ )}

\begin{tabular}{|c|c|c|c|c|}
\hline \multirow[b]{2}{*}{ Periodo } & \multicolumn{2}{|c|}{ A. Bocamina-ferrocarril } & \multicolumn{2}{|c|}{ B. Ferrocarril-embarcadero } \\
\hline & $\begin{array}{l}\text { Tarifas medias } \\
\text { de mercado }\end{array}$ & Orconera & $\begin{array}{c}\text { Tarifas medias } \\
\text { de mercado }\end{array}$ & Orconera \\
\hline 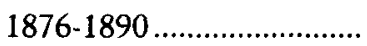 & 0,95 & 0,40 & 2,5 & 0,80 \\
\hline 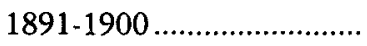 & 0,50 & 0,20 & 2,5 & 0,80 \\
\hline $1901-1913 \ldots \ldots \ldots \ldots \ldots \ldots \ldots$ & 0,60 & 0,20 & 3 & 1 \\
\hline 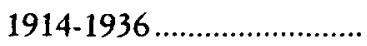 & 1,5 & 0,80 & 4 & 1,5 \\
\hline
\end{tabular}

FUENTES: 1876-1921: Anónimo (1921) (AJL). 1922-1936: Infomación sobre costes elaborada por la Cámara Minera (ACAM).

Los bajos costes y la existencia de precios preferenciales hicieron que la Dowlais, la Consett, la Krupp y Altos Hornos pudieran beneficiar minerales muy baratos, sobre todo en el período de altos precios 1891-1913 (supra, cuadro 1).

La Orconera obtenía beneficios por venta de cupos a precios preferenciales, por venta de excedentes a precios de mercado (1889-1907 y 1921-1936) y también por transportar mineral ajeno en su ferrocarril. Por otro lado, en 1894 comenzó a laborear minas en Santander. Me ha sido imposible confeccionar una serie anual desglosada de esas ganancias, ya que los archivos de Agruminsa fueron destruidos por un incendio - sólo conozco sus resultados entre 1901 y 1935 gracias a las Estadísticas de la Contribución de Utilidades y a los fondos de los archivos del Círculo Minero y Administrativo de la Diputación de Vizcaya $-{ }^{51}$. Ello no obsta para estimar los del período 1876-1900 a partir de algunos datos conocidos. El cálculo requiere distinguir entre ganancias por ventas y por acarreo de mineral ajeno.

La empresa vendió toda su producción a precios preferenciales durante los años 1876-1888, de manera que, multiplicando aquélla por 1 chelín y 7 peniques al cambio, obtendremos sus beneficios en pesetas. El mismo procedimiento servirá para calcular sus ganancias por cupos concertados entre 1889 y 1900 , si bien en este período habrá que sumarles las utilidades

${ }^{51}$ La documentación de la Orconera y de la Franco Belga se hallaba en ese archivo porque ambas empresas fueron adquiridas por Altos Hornos de Vizcaya en la década de 1940. Los beneficios de la Orconera posteriores a 1920 proceden del Archivo Administrativo de la Diputación, ya que en 1921 se concertaron los impuestos mineros. 
por ventas a precios de mercado. El cuadro 8 contiene esos cálculos, un total de 55,6 millones de pesetas.

\section{CUADRO 8}

Beneficios estimados de la Orconera por ventas de mineral (1876-1900). Minas de Vizcaya

\begin{tabular}{|c|c|c|c|c|c|c|c|c|c|c|c|}
\hline$A$ ños & $A$ & & $B$ & & $C$ & & $D$ & & $E$ & $F$ & $G$ \\
\hline $1876-1888 \ldots \ldots \ldots \ldots \ldots$ & 6,5 & $x$ & 2 & $=$ & 13 & + & 0 & $x$ & 一 & $=0$ & $=13$ \\
\hline $1889-1900 \ldots \ldots \ldots \ldots \ldots$ & 7,2 & $x$ & 2,5 & $=$ & 18 & + & 4,1 & $x$ & 6 & $=24,6$ & $=42,6$ \\
\hline TOTAL. & & & & & & & & & & & 55,6 \\
\hline
\end{tabular}

A: Ventas a precios preferenciales (millones de Tm). B: Beneficio medio (ptas.). C: Beneficios por cupos concertados (millones de ptas.). D: Ventas a precios de mercado (millones de $T \mathrm{~m}$ ). E: Beneficio unitario (ptas.). F: Beneficios por ventas a precios de mercado. G: Beneficios totales por ventas (millones de ptas). El beneficio unitario a precios de mercado lo he estimado restando a los precios medios $\mathrm{f}$. $\mathrm{o}$. b. los costes medios $\mathrm{f}$. $\mathrm{o}$. $\mathrm{b}$. de la Orconera.

A ellos deben añadirse las ganancias de su ferrocarril, que pueden estimarse conociendo el mineral ajeno acarreado y el beneficio unitario: 8,4 millones de $\mathrm{Tm} \times 1,5$ pesetas, es decir, 12,6 millones ${ }^{52}$. Por lo tanto, la Orconera habría obtenido entre 1876 y 1900 beneficios verosímiles de 68,2 millones $(55,6+12,6)$. El cuadro 9 muestra las ganancias reales de la compañía desde principios de siglo a 1935.

La finalidad primordial de la empresa fue abastecer regularmente a sus socios de un input barato para hacer competitivo el acero que producían. Ello explica que, pese a haber sido la compañía más eficiente del sector, sus beneficios sólo fueran extraordinarios entre 1890 y 1906, cuando vendió excedentes de 150.000 a $350.000 \mathrm{Tm}$ a precios de mercado muy remuneradores y cuando transportó más de $200.000 \mathrm{Tm}$ ajenas en su ferrocarril —entonces alcanzó ganancias de 3,5 a 5 millones de pesetas por ejercicio-. Antes de 1890, sus utilidades se situaron en un mínimo de 0,5 millones y un máximo de 2,5 porque acarreó un tonelaje ajeno menor y porque sólo vendió lotes de 200.000 a $600.000 \mathrm{Tm}$ con ganancias medias de 1 chelín y 7 peniques - unas 2 pesetas al cambio--. Los

52 El mineral ajeno acarreado por la compañía lo he estimado restando al tonelaje total transportado la producción de la compañía. El beneficio de 1,5 pesetas procede de Anónimo (1921) y concuerda con las ganancias inedias de la Bilbao River. 


\section{CUADRO 9}

Beneficios de la Orconera (1901-1935). Minas de Vizcaya y Santander (miles de libras y pesetas)

\begin{tabular}{|c|c|c|}
\hline$\overline{A n ̃ o s}$ & Libras & Pesetas \\
\hline 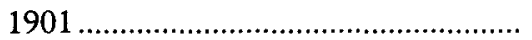 & - & 5.304 \\
\hline 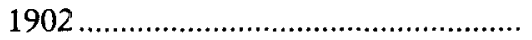 & - & 4.760 \\
\hline 1903 & - & 3.588 \\
\hline 1907 & - & 2.044 \\
\hline 1908 & - & 2.260 \\
\hline 1909 & - & 2.653 \\
\hline 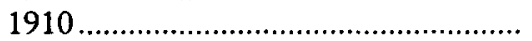 & - & 2.323 \\
\hline 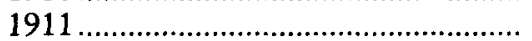 & - & 1.910 \\
\hline 1912 & - & 2.289 \\
\hline 1913 & 120 & 3.240 \\
\hline 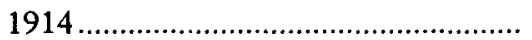 & 60 & 1.572 \\
\hline 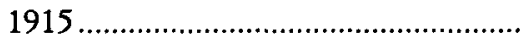 & 40 & 1.080 \\
\hline 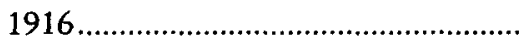 & 100 & 2.390 \\
\hline 1917 & 90 & 1.899 \\
\hline 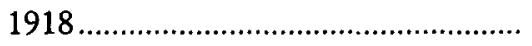 & 100 & 1.980 \\
\hline 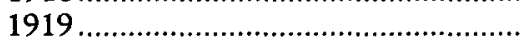 & 80 & 1.792 \\
\hline 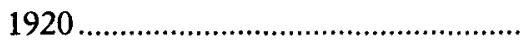 & 90 & 2.088 \\
\hline 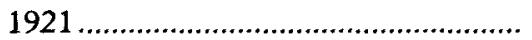 & -21 & -616 \\
\hline 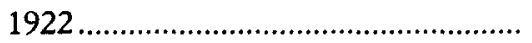 & -8 & -241 \\
\hline 1923 & -22 & -711 \\
\hline 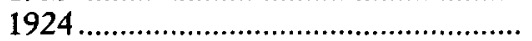 & 86 & 2.870 \\
\hline 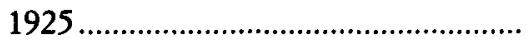 & 92 & 3.099 \\
\hline 1926 & 42 & 1.386 \\
\hline 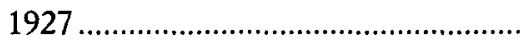 & 87 & 2.488 \\
\hline 1928 & 64 & 1.901 \\
\hline 1929 & 70 & 2.321 \\
\hline 1930 & 82 & 3.452 \\
\hline 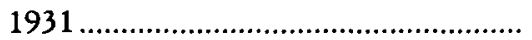 & 27 & 1.322 \\
\hline 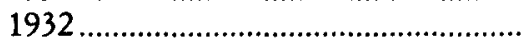 & 27 & 1.311 \\
\hline 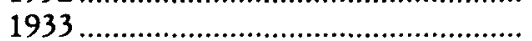 & 21 & 866 \\
\hline 1934 & 31 & 1.152 \\
\hline 1935 & 37 & 1.362 \\
\hline
\end{tabular}

FUENTES: 1901-1913: Estadísticas de la Contribución sobre las Utilidades de la Riqueza Mobiliaria. 1914-1920: ACM. Legajos sobre beneficios durante la Guerra. 1921-1935: AAD. Sección Impuesto de Utilidades.

beneficios descendieron entre 1907 y 1913 al dejar de comercializar excedentes a precios de mercado y al transportar menos mineral ajeno. Tras la Primera Guerra Mundial y una vez que la Krupp la abandonara, la Orconera proporcionó cupos de $500.000 \mathrm{Tm}$ a sus socios y vendió 
excedentes, pero el desplome de los precios, así como el del tonelaje ajeno acarreado en su ferrocarril explican los modestos resultados del cuadro 9 fuera de la coyuntura de mayores ventas y precios de los años 1927-1930.

La compañía repartió dividendos del 6-12 por 100 hasta mediados de los ochenta para subsanar parte de unas inversiones que habían superado el capital desembolsado. Entre 1886 y 1906 —cuando vendió excedentes a precios de mercado-, el dividendo ascendió al $43-53$ por 100, llegando en algunos años (1901 y 1902) al 70 y 78 por 100 -recuérdese que la empresa no realizó entonces ninguna inversión de envergadura fuera de la instalación de hornos, trómeles y un tranvía aéreo-. El porcentaje de los años 1907-1913 continuó siendo elevado (48-78 por 100) porque no se renovó el utillaje ${ }^{53}$. Según Harvey y Taylor, la empresa repartió dividendos por valor de 3,6 millones de libras hasta 1913, lo que significa que reinvirtió muy pocos beneficios ${ }^{54}$. Desde 1920 , en cambio, el dividendo se fijó en un 3 por 100 sobre el capital social, lo que permitió acumular fondos de reserva para financiar la mecanización 55 .

La cuarta de las empresas concentradas verticalmente con la siderurgia europea fue la Franco Belga des Mines de Fer de Somorrostro, constituida en París el 8 de mayo de $1876^{56}$. Se creó con un capital de 3 millones de francos representados por 6.000 acciones de 500 francos cada una. El capital se suscribió del siguiente modo:

- José Antonio de Ibarra

20 acciones

- Ibarra Hermanos y Cía. 580 acciones

- Sociedad Denain et Anzin 1.760 acciones

- Sociedad Montataire

1.740 acciones

- Sociedad John Cockerill

1.760 acciones

- Siete personas extranj. a 20 acciones cada una. 140 acciones

- Total 6.000 acciones $^{57}$.

Dos casas siderúrgicas francesas (Denain y Montataire) adquirieron, respectivamente, el 29,3 y el 29 por 100 de las acciones. La empresa belga Cockeril, el 29,3 por 100 . Los Ibarra, el 10 por 100 , y el otro 2,4 por 100 fue suscrito por siete extranjeros.

53 Los dividendos del período 1877-1913 en Broder (1981), p. 1607.

${ }^{54}$ Harvey-Taylor (1987), p. 195.

${ }^{55}$ Memoria de la compañía de 1921. AAD. Sección Impuesto de Utilidades.

56 Estatutos fundacionales de la Franco Belga. AAD. Sección Impuesto de Utilidades.

57 Estatutos fundacionales. Éstos son los nombres de esas siete personas: M. Martelet, M. Waternau, M. de la Martelliére, M. de Boischevalier, M. de Mous, M. Delloye-Matthiew y M. Sadoine. 
La Franco Belga se creó para explotar durante noventa y nueve años un coto de $120 \mathrm{Ha}$. arrendado a la familia Ibarra en el municipio de Abanto. El canon por tonelada se estipuló en 2 reales ${ }^{58}$. Todo el mineral producido sería adquirido por los socios fundadores a un precio preferencial de 1,5 francos sobre el coste ${ }^{59}$. A diferencia de la Orconera, la empresa nunca vendió excedentes a precios de mercado:

«El fin que se han propuesto los fundadores de esta sociedad ha sido exclusivamente el de alimentar sus fábricas el mayor tiempo posible con el producto de las minas (...), no el vender sus minerales. Sería posible extraer más de $500.000 \mathrm{Tm}$ por año, pero, como queda indicado, la compañía se propone solamente satisfacer las necesidades de sus socios y prefiere asegurar estas necesidades por cuantos más años mejor más bien que agotar rápidamente las minas» ${ }^{60}$.

Los cupos concertados en 1876 fueron estos: Ibarra Hermanos recibirían anualmente un mínimo de $20.000 \mathrm{Tm}$ y un máximo de 40.000 , mientras que la Denain, la Montataire y Cockerill adquiririan mínimos de 40.000 y máximos de $100.000^{61}$. O sea, un mínimo de $140.000 \mathrm{Tm}$ anuales y un máximo de 340.000 . Este lote superior fue aumentado desde 1893 hasta las $600.000 \mathrm{Tm}^{62}$. Los Ibarra cedieron su cupo en 1882 a Altos Hornos de Bilbao.

Las inversiones iniciales de la empresa fueron mucho menores que las de la Orconera:

CUADRO 10

Inversiones de la Franco Belga basta 1883

\begin{tabular}{|c|c|}
\hline & Pesetas \\
\hline 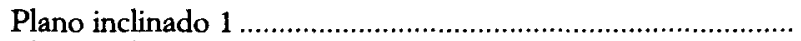 & 210.000 \\
\hline Plano inclinado $2 . . . . . . . . . . .$. & 380.000 \\
\hline 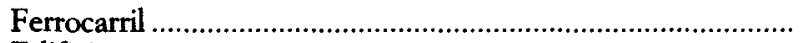 & 2.132 .000 \\
\hline 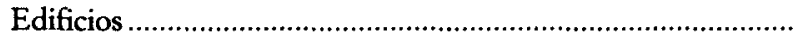 & 750.000 \\
\hline Minas & 350.000 \\
\hline TOTAL & 3.822 .000 \\
\hline
\end{tabular}

FuENTE: Goenaga (1883) y Franco Belga de las Minas de Somomostro (folleto de 1883).

${ }^{58}$ Estatutos fundacionales.

59 Estatutos fundacionales.

60 Franco Belga de las Minas de Somorrostro. Folleto de 1883.

${ }^{61}$ Estatutos fundacionales.

${ }_{62}$ Estatutos reformados de la sociedad, 1893. AAD. Sección Impuesto de Utilidades. 
La razón estriba en el coste de los ferrocarriles. Mientras que el de la Franco Belga tenía sólo 8 kilómetros, el de la Orconera disponía de 18 y de doble vía. Así pues, la compañía hizo frente a las primeras inversiones sin necesidad de recursos complementarios. Entre 1884 y 1890 invirtió otros 1,75 millones de francos, capital que fue aportado por los accionistas en forma de obligaciones amortizadas tan sólo en dos años ${ }^{63}$. A fines de siglo, instaló hornos de calcinar, trómeles, una cadena sin fin y un cable aéreo ${ }^{64}$. La empresa no mecanizó el laboreo hasta después de la Primera Guerra Mundial, invirtiendo entonces 2,2 millones de francos en martillos eléctricos, dragas y mejoras en hornos de calcinación y cargaderos ${ }^{65}$.

Después de la Orconera, la Franco Belga fue la compañía con mayor producción de la cuenca. También alcanzó productividades por encima de la media y laboreó con menores costes:

\section{CUADRO 11}

Franco Belga. Producción de mineral (1876-1936)

\begin{tabular}{|c|c|c|}
\hline$A \bar{n} o s$ & $\begin{array}{c}\text { Media } \\
\text { (miles de } \mathrm{Tm} \text { ) }\end{array}$ & $\begin{array}{c}\text { Porcentaje sobre } \\
\text { la producción vizcaina }\end{array}$ \\
\hline $1876-1885 \ldots \ldots \ldots \ldots \ldots \ldots$ & 136 & 6 \\
\hline $1890-1913 \ldots \ldots \ldots \ldots \ldots$ & 390 & 8,3 \\
\hline $1915-1936 \ldots \ldots \ldots \ldots$ & 172 & 8,2 \\
\hline
\end{tabular}

FuENTES: 1876-1921: Censos de producción del Círculo Minero (AAD). 1922-1926: Estadísticas sobre la producción de mineral de la Diputación (AAD).

La sociedad obtenía beneficios de 1,5 francos por tonelada vendida a precios preferenciales y también por transportar mineral ajeno en su ferrocarril. No he podido elaborar una serie desglosada de los mismos al haberse quemado el archivo de Agruminsa. Ello no obstante, el cuadro 13 contiene sus ganancias en veintisiete de los treinta y siete años comprendidos entre 1876 y 1913, así como la serie completa del período $1914-1936^{66}$.

${ }^{63}$ Broder (1981), p. 1627.

${ }^{64}$ Balzola (15-9-1928).

${ }^{65}$ Memorias de la empresa. AAD. Sección Impuesto de Utilidades.

${ }^{6}$ En algunos de mis trabajos, he calculado los beneficios de la Franco Belga entre 1876 y 1913 mediante el siguiente procedimiento. Primero, multiplicando su producción por 1,5 francos al cambio. Luego, asignando ganancias medias de 1,5 pesetas al tonelaje 


\section{CUADRO 12}

Productividad y costes medios de la Franco Belga y del sector

\begin{tabular}{|c|c|c|c|c|c|c|}
\hline \multirow[b]{2}{*}{ Años } & \multicolumn{2}{|c|}{$\begin{array}{c}\text { Productividad } \\
\text { (kilos por obrero/hora) }\end{array}$} & \multicolumn{4}{|c|}{$\begin{array}{c}\text { Costes medios f. o. } b . \\
\text { (pesetas) }\end{array}$} \\
\hline & $\begin{array}{l}\text { Franco } \\
\text { Belga }\end{array}$ & $\begin{array}{l}\text { Media } \\
\text { sector }\end{array}$ & $\begin{array}{c}\text { Franco } \\
\text { Belga }\end{array}$ & $\begin{array}{c}\text { Grandes } \\
\text { empresas } \\
\text { vascas }\end{array}$ & $\begin{array}{l}\text { Medianas } \\
\text { y pequeñas }\end{array}$ & $\begin{array}{c}\text { Costes } \\
\text { medios } \\
\text { sector }\end{array}$ \\
\hline $1890 \ldots \ldots \ldots \ldots$ & 201 & 168 & 4 & 5,2 & 7 & 5,3 \\
\hline $1897 \ldots \ldots \ldots \ldots$ & 194 & 180 & 5,17 & 6,5 & 8 & 6,5 \\
\hline $1913 \ldots \ldots \ldots \ldots$ & 139 & 130 & 7,3 & 9 & 12 & 10,3 \\
\hline $1925 \ldots \ldots \ldots \ldots$ & 160 & 153 & 17 & - & - & 17,99 \\
\hline $1930 \ldots \ldots \ldots \ldots$ & 170 & 149 & 16,5 & - & - & 18,1 \\
\hline $1936 \ldots \ldots \ldots \ldots$ & 182 & 129 & 18,2 & - & - & 19,7 \\
\hline
\end{tabular}

FUENTES: Las mismas del cuadro 8, salvo Wengenroth y Orconera. Los costes de 1897 proceden de la Revista Minera.

Entre 1880-1884, las utilidades pasaron de 150.000 a más de 500.000 pesetas al aumentar las ventas de 70.000 a $200.000 \mathrm{Tm}$ y al acarrear el ferrocarril más mineral ajeno. Los beneficios crecieron entre 1885 y fines de siglo porque la empresa produjo entonces de 250.000 a $500.000 \mathrm{Tm}$ anuales y llegó a acarrear más de $200.000 \mathrm{Tm}$ ajenas (ganancias de 0,7 a 1,3 millones). Las menores utilidades de los años 1903-1913 (en torno a las 500.000 pesetas) se debieron a la reducción de la producción (250.000-300.000 Tm por ejercicio) y del tonelaje ajeno transportado (menos de $100.000 \mathrm{Tm}$ ). Tras la Primera Guerra Mundial, los beneficios se desplomaron porque las ventas se situaron por debajo de las $120.000 \mathrm{Tm}$ y el ferrocarril pasó a acarrear menos de $80.000 \mathrm{Tm}$ ajenas con muy cortas ganancias medias.

El reparto de beneficios preceptuado en los estatutos era este: 5 por 100 para reservas; 10 por 100 para el Consejo de Administración; 10 por 100 para fondos de amortización, y 75 por 100 para fondos de reserva y reparto de dividendos según el criterio del Consejo ${ }^{67}$. La Franco Belga

ajeno acarreado en su ferrocarril. La suma de las dos partidas arroja beneficios de 27 millones de pesetas. El cuadro 13 contiene las utilidades reales de la empresa en veintiséis de los treinta y siete años comprendidos entre 1876 y 1913, un total de 19,6 millones de pesetas. Si extrapolamos a los ejercicios que faltan en la serie los beneficios más cercanos $(40.000$ ptas. entre 1876-1878; 1,3 millones entre 1899 y 1902; 0,5 millones entre 1904-1907), la suma asciende a 27,6 millones, de manera que mi estimación resulta verosímil.

${ }^{67}$ Estatutos fundacionales. 
capitalizó muy pocos beneficios antes de la Primera Guerra Mundial, ya que entre 1879 y 1913 repartió dividendos por un valor de 20 millones de francos ${ }^{68}$. Las inversiones que luego necesitó la mecanización del laboreo redujeron al 25 por 100 las ganancias distribuidas, llegándose a no pagar dividendos en varios años ${ }^{69}$.

\section{CUADRO 13}

Beneficios de la Franco Belga (1879-1936)

\begin{tabular}{|c|c|c|}
\hline Años & Francos & Pesetas \\
\hline $1879 \ldots \ldots \ldots \ldots$ & 43.506 & 43.506 \\
\hline 1880 & 164.768 & 146.643 \\
\hline 1881 & 283.160 & 280.328 \\
\hline 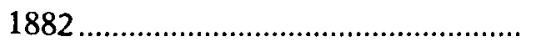 & 466.776 & 471.443 \\
\hline 1883 & 586.735 & 592.602 \\
\hline 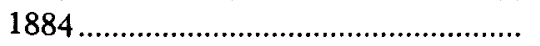 & 577.777 & 583.554 \\
\hline 1885 & 792.345 & 808.191 \\
\hline 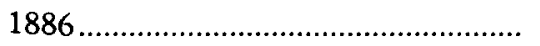 & 729.783 & 744.378 \\
\hline 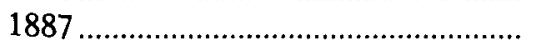 & 838.994 & 847.383 \\
\hline 1888 & 834.851 & 843.199 \\
\hline 1889 & 746.636 & 769.035 \\
\hline 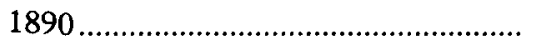 & 1.026 .800 & 1.067 .042 \\
\hline 1891 & 674.702 & 715.184 \\
\hline 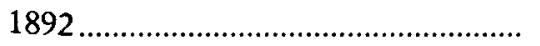 & 871.004 & 1.001 .650 \\
\hline 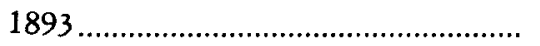 & 961.225 & 1.133 .980 \\
\hline 1894 & 814.818 & 968.662 \\
\hline 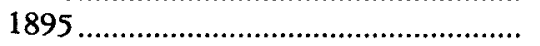 & 806.985 & 839.264 \\
\hline 1896 & 1.136 .578 & 1.363 .200 \\
\hline 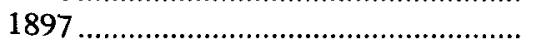 & 1.020 .481 & 1.315 .800 \\
\hline 1898 & 897.470 & 1.381 .000 \\
\hline 1903 & - & 587.512 \\
\hline 1908 & - & 514.801 \\
\hline 1909 & - & 509.161 \\
\hline 1910 & - & 508.129 \\
\hline 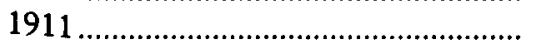 & - & 310.581 \\
\hline 1912 & - & 289.600 \\
\hline 1913 & - & 533.967 \\
\hline 1914 & 130.664 & 135.890 \\
\hline 1915 & 477.959 & 444.501 \\
\hline
\end{tabular}




\begin{tabular}{|c|c|c|}
\hline Años & Francos & Pesetas \\
\hline 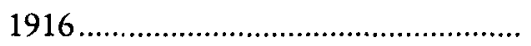 & 543.219 & 461.736 \\
\hline 1917 & 486.798 & 369.966 \\
\hline 1918 & 836.204 & 618.790 \\
\hline 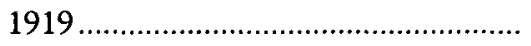 & 631.906 & 454.972 \\
\hline 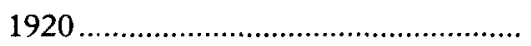 & 764.046 & 336.180 \\
\hline 1921 & 339.028 & 186.465 \\
\hline 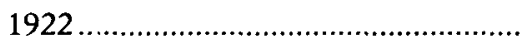 & 481.786 & 250.258 \\
\hline 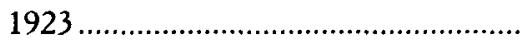 & 582.696 & 238.905 \\
\hline 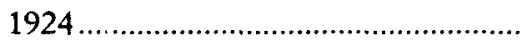 & 343.246 & 130.433 \\
\hline 1925 & 545.565 & 174.580 \\
\hline 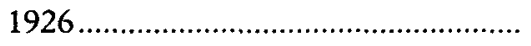 & 166.909 & 35.050 \\
\hline 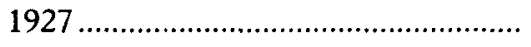 & 734.440 & 161.576 \\
\hline 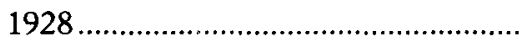 & 961.975 & 221.254 \\
\hline 1929 & 1.404 .935 & 365.283 \\
\hline 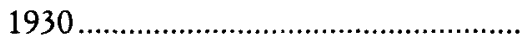 & 846.537 & 279.357 \\
\hline 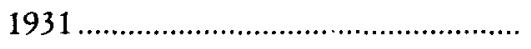 & 179.471 & 71.778 \\
\hline 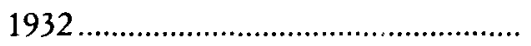 & 93.980 & 45.110 \\
\hline 1933 & -43.149 & -19.843 \\
\hline 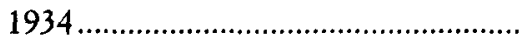 & 69.098 & 33.152 \\
\hline 1935 & 337.900 & 162.192 \\
\hline 1936 & 34.839 & 16.772 \\
\hline
\end{tabular}

FUENTES: 1879-1898: Broder (1981), p. 1629. 1903-1913: Estadísticas de la Contribución sobre las Utilidades de la Riqueza Mobiliaria. 1914-1920: Legajos sobre beneficios durante la Guerra (ACM). 1921-1936 (AAD).

El siguiente cuadro muestra los beneficios verosímiles que las cuatro empresas estudiadas obtuvieron entre 1876 y 1913 :

\section{CUADRO 14}

Beneficios verosimiles de las cuatro empresas vizcainas concentradas verticalmente con la siderurgia europea (1876-1913).

(millones de pesetas)

A. Beneficios por ventas de mineral

B. Beneficios ferrocarriles. $81-90$

* Estos beneficios incluyen las ganancias por ventas a precios preferenciales y las que la Orconera obtuvo comercializando excedentes a precios de mercado.

FUENTE: Escudero (en prensa). 
Los beneficios por ventas merecen un breve comentario. Habiendo producido las cuatro empresas cerca del 30 por 100 del mineral con los menores costes del sector, ascienden sólo a 104 millones. La cifra contrasta con los 229 millones que, según mis estimaciones, obtuvieron los grandes mineros vascos por extraer el 35 por 100 de las menas. La razón estriba en que la Orconera, la Franco Belga, la Luchana Mining y la Bilbao Iron Ore vendieron la inmensa mayoría de sus minerales a precios preferenciales. Así pues, si a los 104 millones añadimos los beneficios invisibles que la siderurgia europea obtuvo consumiendo un input tan barato, habrá que concluir sosteniendo que ésta alcanzó mayores ganancias. Su valor puede «materializarse». Más de 40 millones de $\mathrm{Tm}$ vendidas a 2 pesetas sobre el coste, cuando en el mercado libre hubieran devengado beneficios medios de 6 a 8 pesetas. Si añadimos ese valor invisible transferido al acero - unos 200 millones de pesetas-, el monto de los beneficios foráneos supera al de los grandes mineros vascos. Por otro lado, esos mismos beneficios invisibles no concuerdan con esta conclusión de Harvey, «pesimista» en su trabajo sobre Rio Tinto de 1981, y «optimista» en 1987: «Profits were bard won, and, all in all, were no exceptionally bigh. In the main, factor mobility worked to normalize the rate of return on capital invested. Only for exceptional reasons did an element of economic rent accrue to capital in the case of investment in the copper-pyrites industry ${ }^{70}$.

\section{INTEGRACIONES VERTICALES, BALANZA COMERCIAL Y RELACIÓN DE INTERCAMBIO}

Las cuatro compañías vascas no fueron las únicas concentraciones verticales de la minería española. En el hierro también lo fueron la Marbella Iron Ore, la Alquifes Mines, la Bacares y la Soria Mining, de manera que alrededor del 40 por 100 del mineral de hierro español se vendió a precios preferenciales ${ }^{71}$.

La Tharsis and Sulphur Copper, empresa que extrajo en torno al 20 por 100 de las piritas, era propiedad de varias fábricas británicas de ácido sulfúrico y cobre a las que proporcionó inputs a precios preferenciales ${ }^{72}$.

${ }^{70}$ Harvey-Taylor (1987), p. 205. Ambos autores han estimado tasas de rentabilidad interna de las inversiones extranjeras que rebajan las digamos que convencionales.

71 Para la Marbella Iron Ore, Broder (1981), p. 1613. Para la Alquifes Mines, que laboreó en Granada, Cohen (1987), p. 180. Para The Soria y The Bacares (Almería), Pérez de Perceval (1989), pp. 217 y 222.

${ }^{72}$ Broder (1981), pp. 1454 y 1464. 
La Rio Tinto no fue filial de industrias europeas, ya que pertenecía a un consorcio financiero. Sin embargo, la parte de su producción destinada al Reino Unido debió de exportarse a precios de coste, ya que la empresa poseía en Port Talbot fundiciones donde trataba las piritas y refinaba el cobre. Sería poco razonable pensar que la Rio Tinto se autocompraba esos inputs a precios de mercado porque el negocio consistía en hacer competitivos el azufre y el cobre que vendía después. Otra cosa sucedió con la parte de su producción comprada por los fabricantes de ácido sulfúrico y cobre alemanes, franceses y norteamericanos. En este caso, la sociedad sí que vendió sus materias primas a precios de mercado.

Otra concentración vertical fue la Compagnie Royale Asturienne des Mines, que enviaba sus calaminas a precios preferenciales a la fábrica de cinc que montó en Auby le Douay, al norte de Francia ${ }^{73}$. No puedo asegurar que algunas de las empresas del plomo estuvieran integradas verticalmente con la industria europea de transformación de los galápagos. Éste es un asunto que merecería la pena investigar, ya que la lectura de la Revista Minera y de algunos trabajos de Broder y Chastagnaret me hace sospechar que pudo ser así. De hecho, la agencia Taylor, promotora de las compañías The Linares, The Fortuna y The Alamillos, y también Tom Sopwith, uno de los propietarios de The Spanish Lead Mines, eran accionistas de industrias británicas de transformación del plomo ${ }^{74}$. Por su parte, Hilarion Roux, presidente del Consejo de Administración y principal accionista de la Escombreras Bleyberg, poseía fundiciones en Marsella, mientras que el otro gran accionista de la compañía, la Société Belge des Mines et Fonderies du Bleyberg, disponía de fundiciones en Bélgica $^{75}$. También la empresa de Linares Stolberg y Westfalia transformaba los plomos en sus fábricas alemanas ${ }^{76}$.

Leandro Prados ha estimado la balanza de mercancías y la relación de intercambio en el período de máxima exportación de minerales (1876-1913) ${ }^{77}$. Su cálculo proporciona un superávit acumulado del 15 por 100 en la balanza comercial y un deterioro de la capacidad importadora por unidad exportada, si bien sostiene que ese deterioro no afectó negativamente a la renta española porque provino de un incremento de la productividad. El hecho de que un 40 por 100 del mineral de hierro,

${ }^{73}$ Chastagnaret (1985b).

74 Revista Minera, tomo de 1908, p. 234.

${ }^{75}$ Broder (1981), pp. 1536 y 1538.

${ }^{76}$ Chastagnaret (1985a), p. 756.

77 Prados (1988), pp. 191 y 210-218. 
un porcentaje mayor de las piritas y del cinc y quizás parte del plomo se exportaran a precios preferenciales obliga a cuestionar ambas estimaciones. El saldo de la balanza de mercancías sería menor si contabilizáramos sus ingresos ponderando las cantidades exportadas a precios preferenciales. En cuanto a las relaciones de intercambio, arrojarían un mayor deterioro si pudiéramos construir un índice de los precios de exportación que contemplara la existencia de los preferenciales. Por otro lado, las ganancias de las compañías extranjeras fueron muy superiores a sus beneficios contables dado el valor invisible transferido al acero, al ácido sulfúrico, al cobre refinado o al cinc de las industrias europeas que concentraron verticalmente sus fábricas con las minas, hecho éste que, insisto, no concuerda con las tasas de rentabilidad calculadas por Harvey y Taylor.

Así pues, el debate entre «pesimistas» y «optimistas» debe permanecer abierto en estos y otros aspectos todavía discutibles ${ }^{78}$.

\section{FUENTES Y BIBLIOGRAFÍA}

\section{Archivos}

AAD: Archivo Administrativo de la Diputación de Vizcaya.

AAPM: Archivo de la Asociación de Patronos Mineros.

ACM: Archivo del Círculo Minero.

ACAM: Archivo de la Cámara Minera de Vizcaya.

AJL: Archivo de Julio Lazurtegui.

\section{Revistas}

Revista Minera, Metalúrgica y de Ingeniería.

Boletín Minero. Órgano de la Cámara Minera de Bilbao.

\section{Otras fuentes}

\section{Estadísticas Mineras.}

Estadísticas de la Contribución sobre Utilidades de la Riqueza Mobiliaria.

Anuario Financiero y de Sociedades Anónimas. Ríu Periquet.

Anuario de Mineria. Revista Minera, Metalúrgica y de Ingeniería.

Parliamentary Papers. Consular Reports.

${ }^{78}$ Un estado de la cuestión sobre la controversia acompañado de datos que abundan en el pesimismo, en Escudero (1996). 


\section{Bibliografía}

Anónimo (1921): Contribución al estudio de la mineria vizcaína, AJL, trabajo probablemente escrito por Julio LAZURTEGUI.

BALzOLA, J. (15-9-1928): «La minería en Vizcaya», Boletín Minero.

BRODER. G. (1981): Le rôle des intérêts économiques étrangers dans la croissance de l'Éspagne (1767-1923), thèse pour l'obtention du Doctorat d'État, Université Paris IV, Sorbonne.

CARR, J. C., y TAPLIN, W. (1952): History of the British Steel Industry, Oxford.

COHEN, A. (1987): El Marquesado de Zenete. Tierra de minas, Granada.

CHANDLER, A. (1988): La mano visible. La revolución en la dirección de la empresa norteamericana, Madrid.

- (1996): Escala y diversificación. La dinámica del capitalismo industrial, 2 tomos, Prensas Universitarias de Zaragoza.

Chastagnaret, G. (1985a): Le secteur minier dans l'économie espagnole au XIX siècle, thèse pour l'obtention du Doctorat d'État, Université de Provence.

- (1985b): «Un éxito en la explotación de minerales no férricos españoles en el siglo XIx: la Real Compañía Asturiana de Minas», en BENNASSAR, B., y otros: Orígenes del atraso económico español, Barcelona, pp. 106-130.

EchevarRí, I. (1900): Las minas de bierro de Vizcaya. Progresos realizados en esta región desde 1870 basta 1899, Bilbao.

Elbaum, B. (1986): «The Steel Industry before World War I», en Elbaum, B., y LAZONICK, W. (eds.): The Decline of the British Economy, Oxford.

Escudero, A. (1992): «Trabajo y capital en las minas de Vizcaya», Revista de Historia Industrial, núm. 1, pp. 95-124.

- (1996): «Pesimistas y optimistas ante el boom minero», Revista de Historia Industrial, núm. 10, pp. 69-93.

- (en prensa): Minería e industrialización de Vizcaya, Ed. Crítica, Grijalbo.

FuIN, M. W. (1952): British Overseas Investment in Iron Ore Mining, 1870-1914, M. A. University of Manchester.

- (1955): «British Steel and Spanish ore, 1871-1914», Economic History Rewiew, 2. ${ }^{\mathrm{a}}$ Serie, VIII, núm. 1, pp. 84-90.

Gandolfi, J. (1888): «Las minas de Somorrostro», Revista Minera, tomo de 1888, pp. 109-110.

GILL, W. (1896): «The present position of the Iron Ore Industries of Bizkay and Santander», The Journal of the Iron and Steel Institute, pp. 36-103.

GoenaGa, I. (1883): «El hierro en Vizcaya», Revista Minera, tomo de 1883, pp. 223-225.

GonzÁlez Portilla, M. (1985): La siderurgia vasca (1880-1901), Bilbao.

HARVEY, Ch., y TAYLOR, P. (1987): «Mineral wealth and economic development: foreing direct investment in Spain, 1851-1913m, Economic History Rewiew,

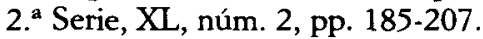

KLeIN, B.; CrawFord, R., y AlChIAN, A. (1978): «Vertical Integration, Appropiable Rents and Competitive Contracting Process», Joumal of Law and Economics, núm. 21, octubre, pp. 297-326.

LazONICK, W. (1991): Business Organization and the Myth of the Market Economy, Nueva York. 
LAZURTEGUI (sin fecha): Las relaciones económicas de Bilbao con Inglaterra, Francia $y$ otros aspectos de la guerra europea que interesan a Vizcaya, Bilbao.

McCloskey, D. M. (1973): Economic Maturity and Entrepeneurial Decline: British Iron and Steel, 1870-1913, Cambridge.

MONTERO, M. (1990): Mineros, banqueros y navieros, Bilbao.

PRADOS DE LA EscosuRA, L. (1988): De Imperio a Nación, Madrid.

Pérez de Perceval, M. A. (1989): La minería almeriense contemporánea, Almería. PERRY, M. K. (1989): «Vertical Integration: Determinants and Effects», en SChMALENSEE y Willig (eds.), pp. 183-255.

RICHARDSON, H.W., y BASS, J. M. (1965): «The profitability of Consett Iron Company before 1914», Business History, VII, pp. 71-93. Este artículo está reproducido en BoYNs, T. (ed.) (1997): The Steel Industry, Londres, tomo 2, pp. 290-312.

RosÉS VENDOIRO, J. R. (1997): «La integración vertical en el sector algodonero catalán, 1832-1861», en López García, S., y Valdaliso, J. M. (eds.): ¿Que inventen ellos? Tecnologia, empresa y cambio económico en la España Contemporánea, Madrid, pp. 249-281.

SChmalensee, R., y WILlig, R. D. (eds.) (1989): Handbook of Industrial Organization, Amsterdam, North Holland, 2 vols.

Sin firma (1883): Orconera Iron Ore, Exposición Nacional de Mineria, Artes, Metalurgia, Cerámica, Cristaleria y Aguas Minerales, folleto, Madrid,

Sin firma (1883): Franco Belga de las Minas de Somorrostro, Exposición Nacional de Mineria, Artes, Metalurgia, Cerámica, Cristaleria y Aguas Minerales, folleto, Madrid.

Sin firma (15-6-1926): «Orconera», Boletín Minero.

TORRES Villanueva, E. (1993): «Estrategia y estructura del grupo industrial Sota y Aznar. Un análisis de coste de transacción», en VELARDE, J.; García DELGADO, J. L., y Pedreño, A. (eds.): Empresas y empresarios españoles en la encrucijada de los noventa, Madrid, pp. 71-104.

WENGENROTH, U. (1984): «Multinational activities in acquering processing of Iron Ore before World War I», EUI, Colloquium Papers, The Early Phase of Multinational Enterprise in Germany, France and Italy, Doc. IUE 158/84 (col. 27), European University Institute, Florencia.

Williamson, O. E. (1971): «The Vertical Integration of Production: Market Failure Considerations», American Economic Review, núm. 61, pp. 112-123.

- (1989a): Las instituciones económicas del capitalismo, México.

- (1989b): «Transaction Cost Economics», en Schmalensee y Willig (eds.), pp. $90-116$. 